\title{
Qualidade de Vida no Trabalho: Análise Compara- tiva entre Estagiários e Empregados de Empresa do Oeste Paranaense
}

\author{
Quality of Life at Work: Comparative Analysis Between Trainees and Employees \\ of a Company in western State of Parana (South Brazil)
}

\section{Crislayne Dias Messias Reichert ${ }^{1}$ e Cecília Oderich ${ }^{2}$}

1. Administradora formada pela Universidade Estadual do Oeste do Paraná (UNIOESTE), Campus de Foz do Iguaçu. ORCID: 0000-0002-3599-9534.

2. Administradora, Mestre e Doutora em Administração (PPGA/UFRGS). Professora adjunta da Universidade Estadual do Oeste do Paraná (UNIOESTE), Campus de Foz do Iguaçu. ORCID: 0000-0002-1776-7019.

crisdias.ms@gmail.com e cecilia.oderich@unioeste.br

\section{Palavras-chave}

Qualidade de Vida

Estágio

Trabalho Profissional

\section{Keywords}

Quality of Life

Internship

Professional work
Artigo recebido em: 19.07.2021.

Aprovado para publicação em: 22.09.2021.

\begin{abstract}
Resumo:
O estágio constitui etapa relevante de aprendizado teórico-prático na formação profissional de estudantes. O presente estudo objetivou realizar uma análise comparativa entre a percepção de 70 estagiários e 108 empregados do setor administrativo de uma empresa de grande porte do oeste do Paraná sobre qualidade de vida no trabalho (QVT), com base no instrumento de pesquisa WHOQOL-100, o qual possui vinte perguntas organizadas, contemplando quatro domínios: físico/saúde, psicológico, pessoal e profissional. Em relação à análise entre os grupos, foi utilizado o teste T-Student, para efeito de comparação entre os valores encontrados, evidenciando que os estagiários da empresa possuem uma percepção de QVT melhor do que a dos empregados. Os domínios estão relacionados a aspectos dos colaboradores, bem como à organização, no sentido das condições de trabalho, benefícios sociais e atitudes de responsabilidade social. Inferese que os empregados tendem a ser mais críticos quanto às condições oferecidas pela empresa. A pesquisa abre novas perspectivas de aprofundamento, tanto para a administração quanto para a educação, na compreensão de tendências e especificidades dos campos de emprego e de estágio, de atuação e formação profissional.
\end{abstract}

\begin{abstract}
:
The internship is a relevant stage of theoretical and practical learning in the professional training of students. This study aimed to carry out a comparative analysis between the perception of 70 interns and 108 employees in the administrative sector of a large company in Oeste Paranaense on quality of life at work (QWL), based on the WHOQOL-100 research instrument, which has twenty organized questions, covering four domains: physical/health, psychological, personal and professional. Regarding the analysis between the groups, the T-Student test was used to compare the values found, showing that the company's interns have a better perception of QWL than the employees. The domains are related to aspects of employees, as well as organization, in the sense of working conditions, social benefits and attitudes of social responsibility. It is inferred that employees tend to be more critical about the conditions offered by the company. The research opens up new perspectives for deepening, both for administration and for education, in the understanding of trends and specificities in the fields of employment and internship, performance and professional training.
\end{abstract}

REICHERT, C.D.M.; ODERICH, C. Qualidade de Vida no Trabalho: Análise Comparativa entre Estagiários e Empregados de Empresa do Oeste Paranaense.
Pleiade, 15(33): 45-62, Jul.-Dez., 2021

DOI: $10.32915 /$ pleiade.v15i33.708 


\section{INTRODUÇÃo}

Cada vez mais o assunto de Qualidade de Vida (QV) vem fazendo parte de contextos diferenciados, que não buscam apenas a avaliação da QV propriamente dita, mas as relações que podem existir entre tal variável e outras facetas da vida (Cheremeta et al., 2011). A satisfação que o funcionário tem em seu ambiente corporativo e nas as atividades exercidas está relacionada com a Qualidade de Vida no Trabalho (QVT), tema desafiador para estudiosos e organizações.

O estágio faz parte da formação profissional e constitui etapa relevante de aprendizado teórico-prático, geralmente, também, representando a inserção no mercado de trabalho e período de experiência no cotidiano e na cultura organizacional. É um momento valorizado na vida dos estudantes, pois estes podem aprender na prática, contando com orientação e supervisão profissional. Considerando as diferenças de forma de contratação e de fase de vida entre funcionários e estagiários, surgiu a ideia de investigar a percepção da QVT, ou seja, se haveria diferença significativa de percepção entre estagiários que estão em aprendizado, começando a carreira profissional, e profissionais já veteranos, considerando os aspectos envolvidos no cenário da QVT, com base no instrumento de pesquisa WHOQOL-100, que abrange fatores que definem o nível de bem-estar e satisfação que os colaboradores encontram na organização.

Os contextos vividos na organização refletem no estilo de vida, horários de trabalho, na alimentação, lazer, nas relações e na própria visão de mundo das pessoas, que estão diretamente ligados aos fatores da QVT (Limongi-França, 2004). A finalidade da QVT na organização é constituir condições favoráveis para que os colaboradores realizem suas funções em um ambiente estimulante, que otimize o trabalho e mantenha a alta produtividade (Prestes; Vireira, 2017).

O estagiário, em geral, tem como característica ser jovem e querer construir uma perspectiva de carreira. E entre as atividades mais relevantes para a formação e desenvolvimento profissional se destacam justamente as experiências de estágio. Pode-se dizer que elas servem como uma aproximação da realidade do mundo do trabalho. Portanto, o estagiário é um profissional em começo de carreira que geralmente possui um encantamento pelo ambiente corporativo. Enquanto os empregados, que são veteranos, estão com a carreira profissional definida e com mais experiências no ambiente organizacional, o que pode levar a uma percepção diferente em relação à percepção dos estagiários. Assim, este artigo tem por objetivo analisar comparativamente a percepção dos empregados e dos estagiários em relação à QVT, através de um instrumento de avaliação va lidado. Para tanto, pretende-se responder à questão: qual a diferença da percepção entre estagiários e empregados do setor administrativo de uma empresa de grande porte do oeste do Paraná em relação à QVT?

Portanto, este trabalho objetivou levantar a percepção sobre a QVT de empregados e estagiários e, na sequência, comparar os resultados obtidos. O artigo apresenta a temática da qualidade de vida no trabalho, seguida da caracterização, semelhanças e diferenças entre emprego formal e estágio, para então destacar os procedimentos metodológicos utilizados e apresentar a análise dos dados e as considerações finais.

\section{QUALIDADE DE VIDA No TRABALHO}

“A Organização Mundial da Saúde (OMS) define qualidade de vida como sendo a percepção que uma pessoa tem da sua vida, no contexto do sistema de valores e da cultura em que vive, em relação a suas metas, expectativas, padrões e interesses” (Siqueira, 2014, p. 31), isto é, define como estado de bem-estar físico, mental e social. 
O tempo dedicado por uma pessoa ao trabalhar diariamente faz com que o trabalho se torne um elemento central, alterando os níveis de satisfação dos elementos e influenciando a QV. Portanto, não é possível analisar a qualidade de vida do ser humano sem levar em consideração a sua vida dentro do ambiente de trabalho, sendo assim, surge a QVT (Reis Júnior, 2008). O conceito, por ser utilizado como alicerce em muitas pesquisas científicas, acabou sendo ampliado, a exemplo de Roeder (apud Reis Júnior, 2008), que incluiu os diversos domínios como a saúde física, a saúde psicológica, as relações sociais e o meio ambiente.

Os quatro domínios, físico/saúde, psicológico, pessoal e profissional foram elaborados com base no instrumento WHOQOL-100 (World Health Organization Quality of Life), instrumento de qualidade de vida da OMS, composto por cem questões sobre avaliação de qualidade de vida e constituído por seis domínios: domínio físico, domínio psicológico, nível de independência, relações sociais, meio ambiente e espiritualidade/religião/crenças pessoais. Sendo assim, dois dos quatro domínios, o físico e o psicológico, pertencem também ao WHOQOL-100. O domínio pessoal tem relação com quatro dos domínios do WHOQOL-100: nível de independência, relações sociais, meio ambiente e espiritualidade/religião/crenças pessoais. E o domínio profissional foi feito pelo fato de o instrumento ter o objetivo de medir a QV especificamente no trabalho (Reis Júnior, 2008). O domínio físico/saúde avalia aspectos como qualidade do sono; qualidade da alimentação; hereditariedade; sensação de conforto; cansaço; satisfação das necessidades fisiológicas básicas; doenças crônicas; atividade física; ginástica laboral; atendimento médico e estresse (Reis Júnior, 2008). Segundo Limongi-França (2004), o estresse representa um aspecto importante no domínio físico/ saúde, e os diversos sintomas como cefaleias, dores estomacais e dores lombares, que certamente diminuem o poder de concentração dos colaboradores na tarefa, diminuindo assim o seu índice de QVT. Maslow (1973) apud Reis Júnior (2008) garante que a satisfação das necessidades básicas do ser humano é fundamental para a qualidade de vida de um indivíduo, como Mendes e Leite (2004) ressaltam que a QV dentro e fora do trabalho são inseparáveis, a satisfação das necessidades básicas é fundamental para uma boa QVT, caso contrário podem surgir descontentamentos e a redução da produtividade do colaborador.

Para Reis Júnior (2008), o domínio psicológico abrangeu os seguintes indicadores na sua avaliação: autocontrole; autoestima; espírito de camaradagem; grau de responsabilidade; liberdade de expressão; orgulho do trabalho e segurança. Walton (1973) apud Reis Júnior (2008) verifica a necessidade de autocontrole como sendo imprescindível para se atingir bom nível de QVT. De acordo com o autor, o trabalho está cada vez mais fracionado e supervisionado, o que gera sentimentos desfavoráveis ao desempenho, como tensão e sentimento de falta de autonomia e confiança.

No domínio pessoal Reis Júnior (2008) considera aspectos como: autoavaliação; lazer próprio e da famí lia; moradia; mudanças geográficas; preconceitos; privacidade pessoal; realização pessoal; relação chefe/subordinado; relação trabalho/família; cultura familiar; respeito dos colegas e dos superiores; transporte/mobilidade; valores e crenças pessoais; valores familiares. Neri (1995), citado por Reis Júnior (2008), faz relação do domínio pessoal ao atendimento das expectativas dos colaboradores, relacionando pessoas, trabalho e organização, simultaneamente e de forma ampla.

O domínio profissional é o que apresenta o maior número de indicadores avaliados, são eles: absenteísmo; assistência médica; autonomia; burocracia; carga horária; cooperação entre níveis hierárquicos; credibi lidade do superior; criatividade; educação; equidade interna e externa; estabilidade de horários; habilidade e disponibilidade de empregados; identidade com a tarefa; imagem da empresa (orgulho); acidentes de trabalho; informações sobre os processos totais do trabalho; metas e objetivos; nível de desafio; participação nas decisões; partilha de ganhos na produtividade; plano de carreira e aprendizagem; remuneração; retroalimen- 
tação/reconhecimento do seu trabalho; treinamento; variedade da tarefa e vida pessoal preservada (Reis Júnior, 2008). A relação entre a responsabilidade social da empresa e a QVT foi apresentada por Drucker (1981) apud Reis Júnior (2008), ao alegar que essas atitudes, obrigatórias ou não, adotadas pelas organizações são fundamentais para a elevação da QVT.

As iniciativas de QVT têm dois objetivos: de um lado, aumentar a produtividade e o desempenho; de outro, melhorar a qualidade de vida no trabalho e a satisfação com o trabalho. Muitos supõem que os dois objetivos estão ligados: uma maneira direta de melhorar a produtividade seria a melhora das condições de trabalho e a satisfação com o trabalho, porém, a satisfação e a produtividade do trabalhador não seguem necessariamente trajetos paralelos. Isto não significa que os dois objetivos sejam incompatíveis, nem que sejam totalmente independentes um do outro. Sob determinadas circunstâncias, melhorias nas condições de trabalho contribuirão para com a produtividade (Pilatti; Bejarano, 2005, p. 89).

De acordo com a afirmação é possível compreender que a QVT pode ter os seus objetivos analisados se paradamente, visto que esta possui uma tendência natural de melhorar a produtividade, no entanto não significa que a melhora da QVT resulte no aumento da produtividade. Contudo, se os objetivos forem associados, poderão produzir mudanças satisfatórias para a organização e para o trabalhador (Cheremeta et al., 2011).

\subsection{Qualidade de Vida no Trabalho: dos Primórdios aOs Dias Atuais}

A preocupação com o bem-estar do trabalhador teve início em meados de 1930, com o surgimento da teoria das relações humanas, desenvolvida pelo sociólogo George Elton Mayo, a partir de pesquisas na fábrica de Hawthorne, entre 1927 e 1932 (Gomes et al., 2014). Segundo Pilatti (2005), após a Revolução Industrial, as condições de vida e trabalho não eram satisfatórias e o trabalho era sub-humano. As pessoas vivenciavam situações que as deixavam cada vez mais expostas às doenças e à fadiga, originadas pela falta de higiene e pela realização de esforço excessivo durante extensos períodos de trabalho.

Eric Trist e seus colaboradores foram os precursores dos estudos em QVT em 1950, potencializaram di versas pesquisas no Tavistock Institute of Human Relations, de Londres, estudaram variáveis que futuramente serviriam para desenvolver o conceito de QVT. Os autores desenvolveram uma abordagem sociotécnica da organização a qual abrange o indivíduo, o trabalho e a organização, e apresenta formas de melhorar a vida dos operários no trabalho, com base na análise e reestruturação das tarefas, com o propósito de tornar a vida dos trabalhadores menos árdua (Alves, 2010).

Conforme Vieira (1996), na década de 1970 o movimento pela QVT se manifesta especialmente nos Es tados Unidos, por motivo de preocupação com a competitividade internacional, e o grande sucesso dos esti los e técnicas gerenciais dos programas de produtividade japonesa. No entanto, em 1974, ocorre a grande crise energética e a alta inflação nos EUA, e então todos os esforços das empresas são voltados para a sua própria sobrevivência, ficando de lado o interesse pelo tema QVT. No início da década de 80, pesquisadores notam a insatisfação e a queda do compromisso por parte dos empregados com seus trabalhos e volta à tona o interesse sobre a QVT (Silva, 2013). Influenciados pelo movimento humanista, autores pleiteiam uma concepção de organização do trabalho que considera o atendimento das necessidades humanas, e que não apenas tenha como horizonte o aumento da produtividade e da lucratividade (Sampaio, 2012).

A QVT vem sendo determinada por diferentes autores de diversas maneiras. Porém, quase todas as defi nições acomodam entre si, como característica comum, a compreensão da QVT como um movimento de reação a rigidez dos métodos tayloristas e, de modo consequente, como um instrumento que tem por finalidade 
oportunizar uma maior humanização do trabalho, o aumento do bem-estar dos trabalhadores e uma maior participação destes nas decisões e problemas do trabalho (Santana et al., 2011).

As concepções sobre QVT são dinâmicas e sua evolução pode ser observada, conforme o Quadro 1:

Quadro 1 - Evolução dos conceitos sobre qualidade de vida no trabalho (QVT), com base em Fernandes (1996, p. 42, apud Silva, 2013, p. 38)

\begin{tabular}{|c|c|}
\hline Concepções de QVT & Características \\
\hline $\begin{array}{l}\text { 1. QVT como uma variável } \\
\text { (1959 a 1972) }\end{array}$ & $\begin{array}{l}\text { Reação do indivíduo ao trabalho. Era investigado como melhorar a } \\
\text { qualidade de vida no trabalho para o indivíduo. }\end{array}$ \\
\hline $\begin{array}{l}\text { 2. QVT como uma abordagem } \\
(1969 \text { a } 1974)\end{array}$ & $\begin{array}{l}\text { O foco era o indivíduo antes do resultado organizacional; mas, ao } \\
\text { mesmo tempo, tendia a trazer melhorias tanto ao empregado como à } \\
\text { direção. }\end{array}$ \\
\hline $\begin{array}{l}\text { 3. QVT como um método } \\
(1972 \text { a } 1975)\end{array}$ & $\begin{array}{l}\text { Um conjunto de abordagens, métodos ou técnicas para melhorar o } \\
\text { ambiente de trabalho e tornar o trabalho mais produtivo e mais } \\
\text { satisfatório. QVT era vista como sinônimo de grupos autônomos de } \\
\text { trabalho, enriquecimento de cargo ou desenho de novas plantas } \\
\text { com integração social e técnica. }\end{array}$ \\
\hline $\begin{array}{l}\text { 4. QVT como um movimento } \\
(1975 \text { a } 1980)\end{array}$ & $\begin{array}{l}\text { Declaração ideológica sobre a natureza do trabalho e as relações dos } \\
\text { trabalhadores com a organização. Os termos - administração participativa } \\
\text { e democracia industrial - eram frequentemente ditos como ideais do } \\
\text { movimento de QVT. }\end{array}$ \\
\hline $\begin{array}{l}\text { 5. QVT como tudo (1979 a } \\
\text { 1982) }\end{array}$ & $\begin{array}{l}\text { Como panacéia contra a competição estrangeira, problemas de qualidade, } \\
\text { baixas taxas de produtividade, problemas de queixas e outros problemas } \\
\text { organizacionais. }\end{array}$ \\
\hline 6. QVT como nada (futuro) & $\begin{array}{l}\text { No caso de alguns projetos de QVT fracassarem no futuro, não passará } \\
\text { de um “modismo” passageiro. }\end{array}$ \\
\hline
\end{tabular}

Segundo Pilatti (2012) é visível que o quadro está desatualizado. O teste da história contrariou concepção de 'QVT como nada’, quando transformou permanentemente a preocupação por condições melhores de vida para todos, algo muito além de um modismo passageiro. Hoje pode-se falar em 'QVT como um direito’ que, ao que tudo indica, não pode ser revertido. Deve-se ter claro que QVT é um direito de quem tem trabalho, especialmente diante da situação declinante atual, ou seja, um cenário com tendências de transição do trabalho formal para o informal e o desaparecimento progressivo do emprego tradicional. Para Rodrigues (1999) citado por Silva (2013), os autores clássicos como Maslow e Herzberg se importaram com fatores motivacionais ligados às necessidades humanas, espelhados no desempenho e na autorrealização do indivíduo, e são considerados autores que contribuíram para a evolução do conceito de QVT.

Os limites modernos que envolvem QVT foram traçados através da ênfase no enriquecimento do trabalho, termo utilizado por Herzberg (1968) ao investigar rigorosamente sobre fatores que geravam satisfação e insatisfação no trabalho. Em suas conclusões, Herzberg indicou fatores de satisfação (motivadores), que estão relacionados ao conteúdo do cargo ou com a natureza das tarefas desenvolvidas pelo indivíduo. Portanto são determinados pelo ambiente que envolve o indivíduo e as condições dentro das quais desempenha suas funções e são fatores que apenas previnem a insatisfação (manutenção ou higiênicos). Pillati (2012), explicando o raciocínio de Herzberg, afirma que, “dentro de sua linha de pensamento e com perspectiva do comportamento humano, o antônimo de insatisfação não é necessariamente satisfação. O inverso de insatisfação 
pode ser nenhuma insatisfação” assim como para satisfação que pode ter como oposto nenhuma satisfação (Pilatti, 2012, p. 20).

Nos últimos anos aumentaram as interrogações acerca do bem-estar do homem no trabalho e o termo Qualidade de Vida (QV), ultimamente utilizado para explicar esse bem-estar se tornou cada vez mais popular. Porém, muitas vezes vem sendo usado erroneamente (Martins, 2010). Para Limongi-França (2004, p.24), “as definições de QVT vão desde cuidados médicos estabelecidos pela legislação de saúde e segurança até atividades voluntárias dos empregados e empregadores nas áreas de lazer, motivação, entre inúmeras outras”. Ao longo do tempo, a forma como o trabalhador é visto sofreu grandes transformações, desde a criação das primeiras formas de trabalho, restritas tão somente ao trabalho no campo até a Revolução Industrial em 1776 e a constituição das primeiras teorias administrativas, afluindo até as teorias mais modernas, na qual o ser humano é o foco dos estudos (Reis Júnior, 2008).

“No contexto das organizações, o termo Qualidade de Vida no Trabalho (QVT), cunhado por Louis Davis nos anos 1970, refletia inicialmente a preocupação com o bem-estar geral e a saúde dos indivíduos no desempenho de suas tarefas” (Martins, 2010, p. 131).

Segundo Reis Júnior (2008), ao se considerar quaisquer ambientes de trabalho, é possível perceber vários aspectos relacionados à QVT. Observa-se pequenos conflitos pessoais, pressões, inquietudes, sinais de estresse, hábitos alimentares errôneos, cuidados físicos precários, impactos tecnológicos, e outros aspectos que, sem dúvida, se fazem presentes.

Para Limongi-França (2004), esses acontecimentos acarretam novas atitudes das empresas e provocam mudanças no estilo de vida e de trabalho das pessoas, dando sentido para o debate e a busca de qualidade de vida dentro e fora do ambiente de trabalho.

Os conceitos de motivação de Maslow (1954) referem-se às necessidades humanas, classificadas em: fi siológicas, de segurança, sociais, de autoestima e de autorrealização.

Todavia, o autor apresenta definições feitas a partir da observação dos desejos. "Deseja-se uma coisa para conseguir-se outra, que é a satisfação de uma ou de, na maioria dos casos, duas ou mais necessidades. Um indivíduo pode estar motivado, simultaneamente, por várias necessidades” (Hesketh; Costa, 1980, p.59).

Um indivíduo, com certo nível de necessidade, tem todo o seu organismo orientado para a busca de meios para satisfazer tal necessidade, de sorte que toda a sua percepção, memória e inteligência estão voltadas para os gratificadores adequados. Na medida em que esta necessidade começar a ser satisfeita, a mais próxima na hierarquia, em posição superior, começará a surgir e a dominar o organismo, enquanto la outra passará a existir apenas num estado potencial, podendo, entretanto, ressurgir se houver modificações no ambiente que determinem o seu reaparecimento no indivíduo (Hesketh; Costa, 1980, p.60).

Para Hesketh; Costa (1980), as necessidades básicas continuam com o ciclo dinâmico (privação, domi nação, gratificação, ativação), de modo que todas sejam satisfeitas e ocorra o surgimento da necessidade de autorrealização. A QVT tem por base a visão ampla das necessidades do ser humano em sua forma integral.

\section{EMPREgo FoRMAL E ESTÁgIO: SEMELHANÇAS E DIFERENÇAS}

O estágio é fundamental para que o indivíduo conheça o ambiente de trabalho e contextualize seus conhecimentos acadêmicos. A experiência universitária é um período importante de constante progressão do 
posicionamento do estudante frente ao seu processo de escolha. A trajetória de formação na universidade propicia diferentes experiências ao estudante, que o levam a equiparar-se com a realidade da profissão e à confirmação (ou não) da escolha feita (Silva; Teixeira, 2013).

Segundo a Lei 11.788 de 25 de setembro de 2008:

Art. $1^{0}$ - Estágio é ato educativo escolar supervisionado, desenvolvido no ambiente de trabalho, que visa à preparação para o trabalho produtivo de educandos que estejam frequentando o ensino regular em instituições de educação superior, de educação profissional, de ensino médio, da educação especial e dos anos finais do ensino fundamental, na modalidade profissional da educação de jovens e adultos (Brasil, 2008).

Essa lei foi sancionada em 25 de setembro de 2008, com a finalidade de regulamentar a atividade de estágio obrigatório e não obrigatório. O parágrafo $2^{\circ}$ do Art. $1^{\circ}$ diz que “O estágio visa ao aprendizado de competências próprias da atividade profissional e à contextualização curricular, objetivando o desenvolvimento do educando para a vida cidadã e para o trabalho”. Com base nisso, deduz-se que o objetivo do estágio se resume na contextualização do conteúdo aprendido em sala de aula em um ambiente profissional, o que torna indispensável que as atividades realizadas pelo estagiário tenham relação com o teor do conhecimento adquirido durante seus estudos (Neumann, 2017). O empregado é qualificado no artigo Art. $3^{\circ}$ - "Considera-se empregado toda pessoa física que prestar serviços de natureza não eventual a empregador, sob a dependência deste e mediante salário”. Nesse sentido, o empregado é o trabalhador subordinado que recebe ordens, e que trabalha todos os dias ou periodicamente e é assalariado, isto é, não é um trabalhador que presta seus serviços apenas de vez em quando ou esporadicamente (Brasil, 1943).

Para Valoria et al., (2016), as atividades de estágio são o primeiro contato dos alunos com a realidade da sua área de estudo no mercado de trabalho. Um dos principais meios para alcançar o conhecimento e relacioná-lo com a prática é o estágio. Portanto ele deve ser considerado uma etapa na construção da vida profissional e também da identidade do indivíduo. O quadro 2 apresenta a diferença entre estágio e emprego formal.

A lei do estágio traz uma série de vantagens tanto para o estagiário, que pode se inserir no mercado de trabalho, quanto para as empresas, que podem contratar um novo talento com a isenção de recolhimentos trabalhistas, inclusive muitas organizações contratam posteriormente os estagiários para o quadro de funcionários da empresa. No caso de descumprimento de quaisquer dos direitos previstos ao estagiário, o contrato de estágio passa a ser nulo, e passa a ser reconhecido o vínculo empregatício e o direito ao pagamento de todas as verbas trabalhistas regulares (Brasil, 2008).

As flexibilizações das relações de trabalho fizeram com que os estágios fossem inseridos nas empresas como uma opção de contratação de mão de obra barata. Além de o ingresso aos estágios ser mais fácil, em tese, para quem tem pouca experiência, é a forma como eles podem confirmar sua real vocação para o trabalho e como eles conhecem diretamente as rotinas de trabalho. Em algumas situações os estágios acabaram por perder sua finalidade original, tornando-se algo muito próximo a uma relação empregatícia, deixaram de ter o objetivo pedagógico e de aprendizado, tornando-se apenas mais uma opção para as empresas de contra tação a baixo custo, desvirtuando sua finalidade, dado que elas não tem obrigações com encargos sociais ao incorporarem estagiários visando somente a redução dos custos com empregados (Oliveira, 2009). 
Quadro 2 - Diferença entre estágio e emprego formal, adaptado

da Lei 11.788/2008 e do Decreto-Lei n ${ }^{\circ} 5.452$.

\begin{tabular}{|c|c|c|}
\hline & ESTÁGIO & EMPREGO FORMAL \\
\hline $\begin{array}{l}\text { Jornada de } \\
\text { trabalho }\end{array}$ & $\begin{array}{l}\text { No caso de estudantes de educação especial } \\
\text { e dos anos finais do ensino fundamental a } \\
\text { jornada de trabalho limitada a } 4 \text { horas diárias } \\
\text { e } 20 \text { horas semanais. No caso de estudantes } \\
\text { do ensino superior, da educação profissional } \\
\text { de nível médio e do ensino médio regular é } \\
\text { de } 6 \text { horas diárias e } 30 \text { horas semanais. } \\
\text { Sendo vedada, em qualquer hipótese, a } \\
\text { realização de horas extras. }\end{array}$ & $\begin{array}{l}\text { A jornada diária de trabalho deve ser de no } \\
\text { máximo oito horas. A lei também determina } \\
\text { que o trabalhador não pode fazer mais de } \\
\text { duas horas extras por dia. A jornada máxima } \\
\text { semanal é de } 44 \text { horas regulares. }\end{array}$ \\
\hline Remuneração & Bolsa acrescida de auxílio-transporte. & $\begin{array}{l}\text { Salário, mais remunerações como: Horas } \\
\text { Extras; Adicional Noturno; Adicional de } \\
\text { Periculosidade; Adicional } \\
\text { Insalubridade; DSR; Comissões; } \\
\text { Gratificação; entre outras verbas trabalhistas. }\end{array}$ \\
\hline $\begin{array}{l}\text { Vínculo } \\
\text { empregatício }\end{array}$ & $\begin{array}{l}\text { Termo de estágio/ Contrato de estágio. } \\
\text { Regido pela Lei } 11.788 / 2008 .\end{array}$ & $\begin{array}{l}\text { CTPS (Carteira de Trabalho e Previdência } \\
\text { Social), regido pela CLT (Consolidação das } \\
\text { Leis do Trabalho) Decreto-Lei n }{ }^{0} 5.452\end{array}$ \\
\hline Duração & $\begin{array}{l}\text { A duração do estágio não pode ser superior a } \\
2 \text { anos. Se o estudante for pessoa com } \\
\text { deficiência, o estágio poderá ter duração } \\
\text { maior do que } 2 \text { anos. }\end{array}$ & $\begin{array}{l}\text { O contrato individual de trabalho poderá ser } \\
\text { acordado tácita ou expressamente, } \\
\text { verbalmente ou por escrito, por prazo } \\
\text { determinado ou indeterminado, ou para } \\
\text { prestação de trabalho intermitente. }\end{array}$ \\
\hline $\begin{array}{l}\text { Direitos } \\
\text { concedidos }\end{array}$ & $\begin{array}{l}\text { A cada } 12 \text { meses o estagiário deverá ter } \\
\text { ainda um recesso renumerado de } 30 \text { dias, se } \\
\text { o estágio tiver a duração de, pelo menos, um } \\
\text { ano. Nos contratos com duração inferior a } 12 \\
\text { meses, o recesso deverá ocorrer de forma } \\
\text { proporcional. }\end{array}$ & $\begin{array}{l}\text { Férias, terço de férias, } 13^{\circ} \text { salário, FGTS, } \\
\text { indenização de } 40 \% \text { do FGTS no caso de } \\
\text { dispensa sem justa causa, aviso prévio e } \\
\text { contribuição para o INSS. }\end{array}$ \\
\hline
\end{tabular}

\section{Procedimentos Metodológicos}

Esta pesquisa pode ser classificada como descritiva, de caráter predominantemente quantitativo. O intuito é tratar e analisar os dados coletados a partir de um instrumento definido previamente, levando em consideração o número de ocorrências e suas correlações estatísticas (Chizzioti, 2001). O estudo foi realizado por meio da aplicação da escala Quality of Working Life Questionnaire-bref (QWLQ-bref) de forma online para avaliar a QVT dos empregados e estagiários de uma empresa de grande porte do oeste do Paraná.

Para a coleta de dados foram utilizados dois instrumentos. O primeiro deles é o questionário sociodemográfico, e o segundo e mais importante é o questionário QWLQ-bref. O questionário foi disponibilizado por meio da plataforma Google Formulários, no segundo semestre de 2018. Os participantes foram submetidos a avaliar a QVT seguindo o QWLQ-bref modelo abreviado do questionário de Reis Júnior (2008), o QWLQ78. O instrumento original foi validado em 2008 com base na metodologia WHOQOL-100, e adequado ao ambiente organizacional brasileiro. O QWLQ-bref, foi idealizado por Cheremeta et al., (2011), e é composto por 20 questões subdivididas em quatro domínios seguindo os mesmos critérios do instrumento de QWLQ- 
78. Na versão abreviada são quatro questões de domínio físico/saúde, três de domínio psicológico, quatro de domínio pessoal e nove de domínio profissional o questionário (Facchini et al., 2015).

Com relação à consistência interna, o $Q W L Q$-bref apresentou um coeficiente alfa de Cronbach de valor 0,9035, perfazendo com que tal propriedade psicométrica possa ser considerada como muito alta, superior, inclusive, ao $Q W L Q-78$. Tal qual o $Q W L Q-78$, fora construída para o $Q W L Q$-bref, uma ferramenta para o cálculo dos coeficientes no software Microsoft Excel for Windows. Ao pesquisador compete apenas tabular os dados nos locais especificados, sendo que todos os cálculos são realizados de forma automatizada. A versão final do QLWQ-bref e a ferramenta para o cálculo dos resultados do referido instrumento estão disponíveis no sítio eletrônico http://www.brunopedroso.com.br/qwlq-bref.html. (Cheremeta et al., 2011 p. 14)

O QWLQ-bref apresenta perguntas formuladas organizadas em quatro domínios, conforme exposto no quadro 3 (Facchini et al., 2015).

Quadro 3 - Domínios do QWLQ-bref adaptado por Facchini et al. (2015).

\begin{tabular}{|l|l|}
\hline Domínios & Aspectos Relacionados \\
\hline 1. Físico/Saúde & Saúde, doenças, trabalho e hábitos dos trabalhadores. \\
\hline 2. Psicológico & Satisfação pessoal, motivação no trabalho e autoestima dos trabalhadores. \\
\hline 3. Pessoal & Família, crenças pessoais e religiosas, cultura e de que forma influenciam o trabalho. \\
\hline 4. Profissional & Organizacionais que podem influenciar a vida dos trabalhadores. \\
\hline
\end{tabular}

Seguindo ainda a proposta pelo WHOQOL, Reis Júnior (2008, p. 57), conceitua a QVT como “o conjunto de ações desenvolvidas pelas empresas na implantação de melhorias gerenciais, estruturais e tecnológicas, na busca da satisfação e do bem-estar físico, psicológico, social e profissional dos colaboradores”. As escalas de respostas utilizadas no QWLQ-78 são as mesmas do WHOQOL-100; escalas do tipo Likert de cinco alternativas. De acordo com Cheremeta et al., (2011), afim de analisar os resultados das aplicações do QWLQ-78, Reis Júnior (2008) construiu uma escala de classificação da QVT. A escala em estudo teve como base a ori entação de Siviero (2003), em que todos os índices inferiores a 25 são classificados como insatisfatórios, enquanto os índices situados entre 25 e 75 são classificados como intermediários e os índices superiores a 75 são classificados como satisfatórios. Esta escala foi adaptada para o instrumento QWLQ-78, passando a ter a configuração de "muito insatisfatório" a "muito satisfatório".

Os índices satisfatórios de QVT nessa nova classificação, começam a partir de 55, ou seja, os colaboradores que atingem estes níveis em seus índices possuem uma QVT satisfatória (Cheremeta et al., 2011).

Conforme a metodologia utilizada para a escolha das questões que compõem o WHOQOL-bref, a escolha das questões para constituir a versão abreviada do QWLQ-78, o QWLQ-bref, foi realizada a partir da analogia das questões com o escore global da QVT, calculado a partir da média entre os quatro domínios do instrumento. Essas analogias foram calculadas a partir dos dados apurados por Reis Júnior (2008) da aplicação final do $Q W L Q-78$, em que 378 colaboradores de quatro municípios do estado do Paraná integraram a amostra. Para a formação da versão abreviada do $Q W L Q-78$, foram eleitas as questões do primeiro quartil de cada domínio, mais relacionadas com o escore global da QVT (Cheremeta et al., 2011). 
Uma sintaxe exclusiva foi construída para a tabulação dos dados e cálculo dos resultados do QWLQ-78, criada a partir de algoritmos em planilha eletrônica do programa Microsoft Excel for Windows. Esta sintaxe, além de apresentar os escores da avaliação da QVT, também apresenta a estatística descritiva da pesquisa: a média aritmética simples; o desvio padrão; o coeficiente de variação; o valor mínimo; o valor máximo; a am plitude. Esta apresenta, também, o índice de correlação de Pearson entre os domínios do QWLQ-78 e representa graficamente o resultado dos escores QVT abordados no referido instrumento (Reis Júnior, 2008).

A pesquisa foi realizada em empresa de grande porte do oeste de Paraná, que possui 4 unidades: a matriz e um escritório em Foz do Iguaçu, um em Curitiba e um em Brasília. Optou-se pela aplicação dos instrumentos apenas na matriz da empresa, e especificamente no setor administrativo. Quanto a população, obteve-se um retorno de 178 do total de 378 colaboradores, aproximadamente 47\% de respondentes. Utilizou-se, portanto, amostra não-probabilística, devido ser trabalhado com a população disponibilizada pela empresa.

Apesar da amostra ser não-probabilística atendeu aos critérios sugeridos por Hair et al., (2009) de retorno e validade. "Uma regra geral é que a razão jamais deve ficar abaixo de 5 para 1, o que significa que deve haver cinco observações para cada variável independente na variável estatística” (Hair et al., 2009, p. 168). Portanto para esta pesquisa a proporção entre as observações e variáveis independestes foi de 8 para 1 superando os critérios de observações mínimas. O quadro 4 apresenta as características da amostra.

Quadro 4 - Características da amostra obtida a partir do questionário sociodemográfico (2018)

\begin{tabular}{|c|c|c|}
\hline & CARACTERÍSTICAS DA AMOSTRA $(N=178)$ & $\mathrm{N}(\%)$ \\
\hline \multirow[b]{2}{*}{ Vínculo com a empresa } & Estagiário (a) & $70(39,3)$ \\
\hline & Empregado (a) & $108(60,7)$ \\
\hline \multirow[b]{2}{*}{ Gênero } & Homens & $107(60,1)$ \\
\hline & Mulheres & $71(39,9)$ \\
\hline \multirow[b]{3}{*}{ Idade (em anos) } & De 18 até 30 & $83(46,5)$ \\
\hline & De 31 até 45 & $75(42,2)$ \\
\hline & De 46 até 65 & $20(11,3)$ \\
\hline \multirow{5}{*}{ Escolaridade } & Médio completo & $6(3,4)$ \\
\hline & Técnico & $3(1,7)$ \\
\hline & Superior incompleto & $77(43,3)$ \\
\hline & Superior completo e/ou Pós-graduação incompleta & $43(24,1)$ \\
\hline & Pós-graduação e/ou Mestrado (ou equivalente) & $49(27,5)$ \\
\hline \multirow{5}{*}{ Tempo de empresa } & até 01 ano & $61(34,3)$ \\
\hline & entre 01 e 02 anos & $27(15,2)$ \\
\hline & entre 03 e 6 anos & $22(12,4)$ \\
\hline & entre 07 e 10 anos & $21(11,8)$ \\
\hline & acima de 10 anos & $47(26,4)$ \\
\hline
\end{tabular}




\section{ANÁlise Dos Resultados}

Com a finalidade de apurar confiabilidade dos dados, foram realizados testes para traçar um perfil acerca da QVT. As tabelas e gráficos a seguir demonstram o resultado geral do estudo com relação a empregados e estagiários. No que diz respeito à estatística descritiva, foram analisados a média, o desvio padrão, o coeficiente de variação, o valor mínimo, o valor máximo e a amplitude entre os quatro domínios do instrumento.

Tabela 1 - Estatística Descritiva da Pesquisa com os Empregados através do QWLQ-bref (2018)

\begin{tabular}{l|l|c|c|c|c|c}
\hline \multicolumn{1}{c|}{ DOMÍNIO } & MÉDIA & $\begin{array}{c}\text { DESVIO } \\
\text { PADRÃO }\end{array}$ & $\begin{array}{c}\text { COEFICIENTE } \\
\text { DE VARIAÇÃO }\end{array}$ & $\begin{array}{r}\text { VALOR } \\
\text { MÍNIMO }\end{array}$ & $\begin{array}{r}\text { VALOR } \\
\text { MÁXIMO }\end{array}$ & AMPLITUDE \\
\hline Físico/Saúde & 3,623 & 0,609 & 16,811 & 1,500 & 5,000 & 3,500 \\
\hline Psicológico & 3,815 & 0,759 & 19,894 & 1,000 & 5,000 & 4,000 \\
\hline Pessoal & 3,956 & 0,671 & 16,971 & 1,250 & 5,000 & 3,750 \\
\hline Profissional & 3,541 & 0,683 & 19,300 & 1,000 & 5,000 & 4,000 \\
\hline QVT & 3,734 & 0,581 & 15,562 & 1,500 & 4,861 & 3,361 \\
\hline
\end{tabular}

De acordo com Hair Jr. et al., (2009), o desvio padrão da confiabilidade atesta o tamanho da amostra, ou seja, um bom desvio tem que ser menor ou igual a 3. Como pode-se observar nas quatro dimensões o desvio padrão foi inferior a 3 , indicando que a pesquisa teve quantidade de amostra adequada. Pode-se verificar, na tabela 2, a matriz de correlação entre os quatro domínios e os resultados obtidos.

Tabela 2 - Índice de Correlação de Pearson da Pesquisa com Empregados do QWLQ-bref (2018)

\begin{tabular}{l|l|l|l|l|l}
\hline & & 2 & 3 & 4 & 5 \\
\hline Físico/Saúde (1) & & & & & \\
\hline Psicológico (2) & 0,496139 & & & & \\
\hline Pessoal (3) & 0,474751 & 0,731313 & & & \\
\hline Profissional (4) & 0,489624 & 0,76927 & 0,805179 & & \\
\hline QVT (5) & 0,705189 & 0,894042 & 0,888874 & 0,906181 & \\
\hline
\end{tabular}

Os quatro domínios apresentaram alto índice de correlação entre si e com a QVT. Para Souza (2017). Os valores médios de correlação entre os itens são considerados adequados quando forem superiores a 0,30. "Valores próximos a 1,00 indicam haver correlação, enquanto valores próximos de 0,00 indicam que não há correlação. São desejáveis coeficientes de correlação de 0,70 ou superiores” (Souza, 2017, p. 653).

Os índices de QVT dos 4 domínios que podem ser mais bem visualizados em uma escala de 0 a 100, de acordo com o gráfico 1.

Com os resultados obtidos na pesquisa pôde-se avaliar por intermédio do modelo utilizado para o levantamento de dados, que as respostas encontradas em escala de 0 a 100 apontam para uma QVT do ponto de vista do avaliado com média 68,34\%.

O domínio profissional com 63,53\% foi o que apresentou menor média entre os avaliados, sendo que o domínio pessoal com 73,9\% foi o que apresentou melhor média entre os avaliados. Os outros domínios apresentaram as seguintes médias em escala crescente de avaliação: domínio físico/saúde com média 65,57\% e domínio psicológico com média 70,37\%. Constatou- se que a percepção dos colaboradores foi positiva para 
os quatro domínios mensurados pois a média para QVT resultou em 68,34\%. Esses índices demonstram que os entrevistados percebem a QVT como satisfatória.

Gráfico 1 - Média dos Domínios da QVT do Ponto de Vista dos Empregados e Média Geral do QWLQ-bref (2018)

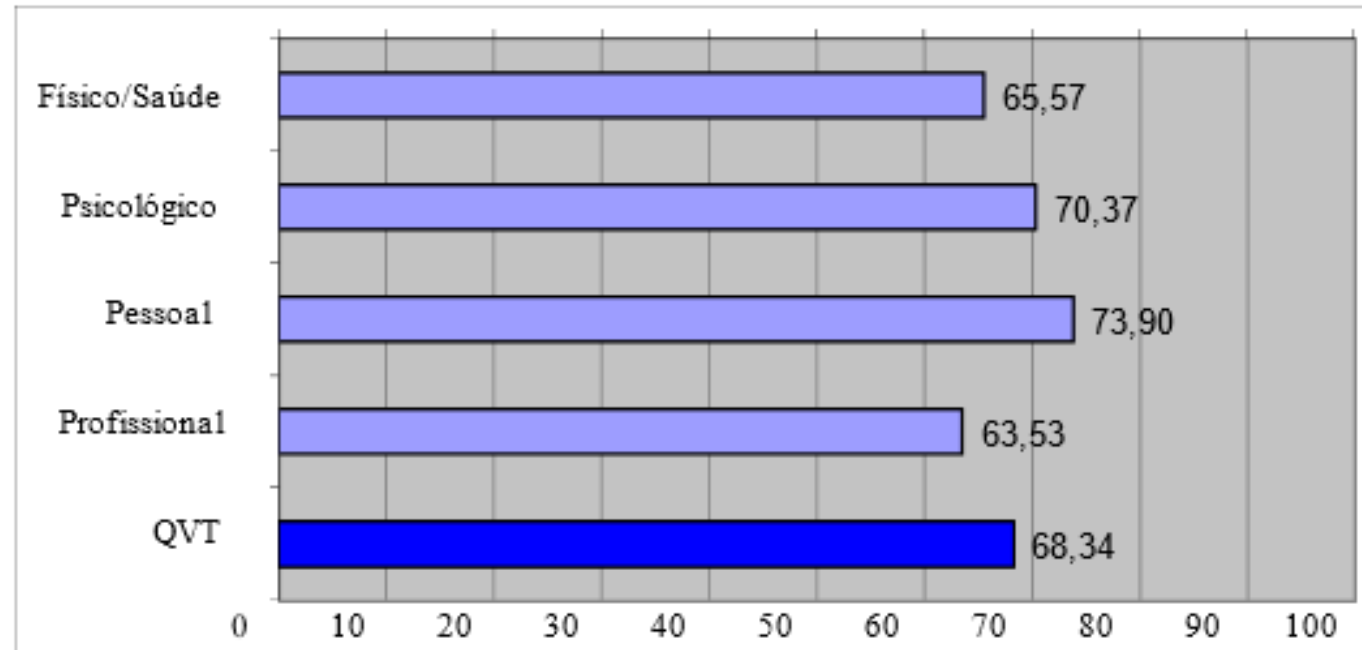

Em relação à QVT dos estagiários, a estatística descritiva os resultados apresentados são os seguintes.

Tabela 3 - Estatística Descritiva da Pesquisa com Estagiários através do QWLQ-bref (2018)

\begin{tabular}{l|l|c|l|c|c|l}
\hline \multicolumn{1}{c|}{ DOMÍNIO } & MÉDIA & $\begin{array}{c}\text { DESVIO } \\
\text { PADRÃO }\end{array}$ & $\begin{array}{c}\text { COEFICIENTE } \\
\text { DE VARIAÇÃO }\end{array}$ & $\begin{array}{c}\text { VALOR } \\
\text { MÍNIMO }\end{array}$ & $\begin{array}{c}\text { VALOR } \\
\text { MÁXIMO }\end{array}$ & AMPLITUDE \\
\hline Físico/Saúde & 3,550 & 0,575 & 16,201 & 2,250 & 4,750 & 2,500 \\
\hline Psicológico & 3,976 & 0,645 & 16,231 & 2,333 & 5,000 & 2,667 \\
\hline Pessoal & 4,257 & 0,526 & 12,366 & 2,750 & 5,000 & 2,250 \\
\hline Profissional & 3,820 & 0,652 & 17,075 & 1,889 & 5,000 & 3,111 \\
\hline QVT & 3,901 & 0,491 & 12,589 & 2,528 & 4,729 & 2,201 \\
\hline
\end{tabular}

Na tabela 4 é apresentada a correlação entre os quatro domínios e os resultados obtidos foram os seguintes com os estagiários.

Tabela 4 - Índice de Correlação de Pearson da Pesquisa com Estagiários do QWLQ-bref (2018)

\begin{tabular}{l|l|l|l|l|l}
\hline & 1 & 2 & 3 & 4 & 5 \\
\hline Físico/Saúde (1) & & & & & \\
\hline Psicológico (2) & 0,318868 & & & & \\
\hline Pessoal (3) & 0,435588 & 0,690162 & & & \\
\hline Profissional (4) & 0,498654 & 0,646541 & 0,758125 & & \\
\hline QVT (5) & 0,679891 & 0,821572 & 0,87404 & 0,893669 & \\
\hline
\end{tabular}


Assim como para os empregados, no caso dos estagiários os quatro domínios apresentaram alto índice de correlação entre si e com a QVT. O gráfico 2 apresenta os índices de QVT dos 4 domínios que podem ser mais bem visualizados em uma escala de 0 a 100.

Gráfico 2 - Média dos Domínios da QVT do Ponto de Vista dos Estagiários e Média Geral do QWLQ-bref (2018)

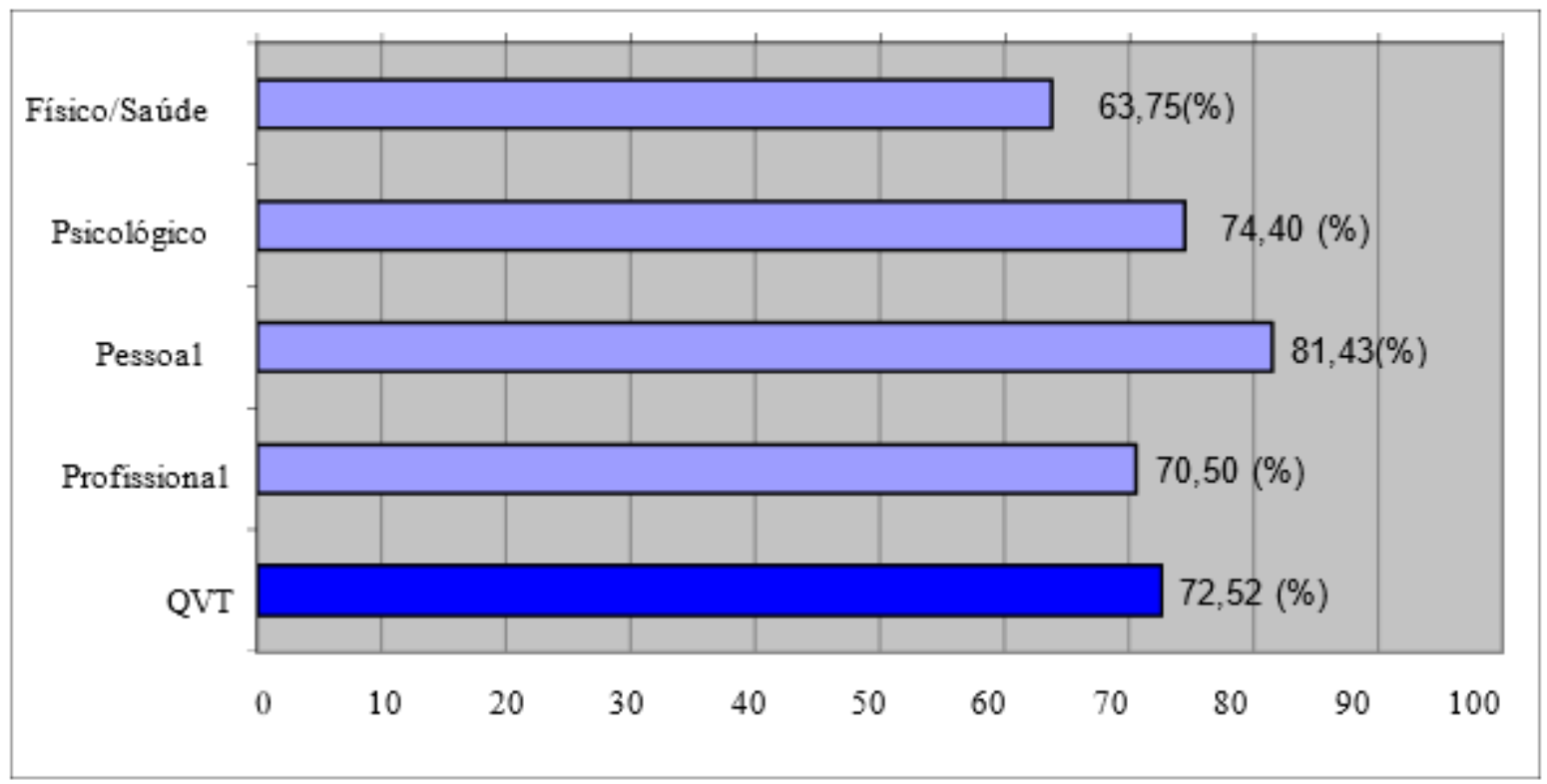

Constatou-se que a percepção dos estagiários é positiva para os quatro domínios mensurados, uma vez que a média para QVT resultou em 72,52\%.O domínio físico/saúde (63,75\%) foi o que apresentou menor média entre os avaliados e o domínio pessoal $(81,43 \%)$ foi o que apresentou melhor média. Os outros domínios apresentaram as seguintes médias em escala crescente de avaliação: domínio profissional (70,5\%) e domínio psicológico (74,4\%). Conclui-se, portanto, através dos resultados obtidos na escala Likert, que os estagiários têm a percepção da QVT também satisfatória, porém, um tanto mais alta se comparada à percepção dos empregados.

\subsection{ANÁLISE COMPARATIVA ENTRE EMPREgADOS E ESTAGIÁRIOS}

Para analisar comparativamente com maior propriedade os dados anteriormente apresentados, os quais indicavam uma maior satisfação dos estagiários em relação à QVT, em relação aos empregados, foi utilizado o teste T-Student, um teste de hipótese que usa conceitos estatísticos para rejeitar ou não uma hipótese nula quando a estatística de teste $(T)$ segue uma distribuição $T$ de Student. Ele pode ser conduzido para comparar uma amostra com uma população, comparar duas amostras pareadas ou comparar duas amostras independentes (Lopes et al., 2015). Foi utilizado o teste T-Student bicaudal para efeito de comparação entre os valores encontrados, os dados foram rodados através do programa SPSS que é um software para análise estatística, para realizar análises dinâmicas dos dados coletados em uma pesquisas (Mundstock, 2006) A análise estatística teve como critério o nível de significância $<0,05$ com o grau de liberdade normal, como mostra a tabelas 5 e 6. 
Tabela 5 - Estatísticas de Significância de uma amostra - Dados obtidos e trabalhados pelas autoras (2019)

\begin{tabular}{|l|l|r|r|r|}
\hline & & Média & Desvio Padrão & $\begin{array}{c}\text { Erro padrão da } \\
\text { média }\end{array}$ \\
\hline QVT_EMPREGADO & 108 & 3,7337 &, 5810 &, 05591 \\
QVT_ESTAGIÁRIO & 70 & 3,9008 & 0 &, 05869 \\
& & & 6 & \\
\hline
\end{tabular}

Tabela 6 - Teste de uma amostra - Dados obtidos e trabalhados pelas autoras (2019)

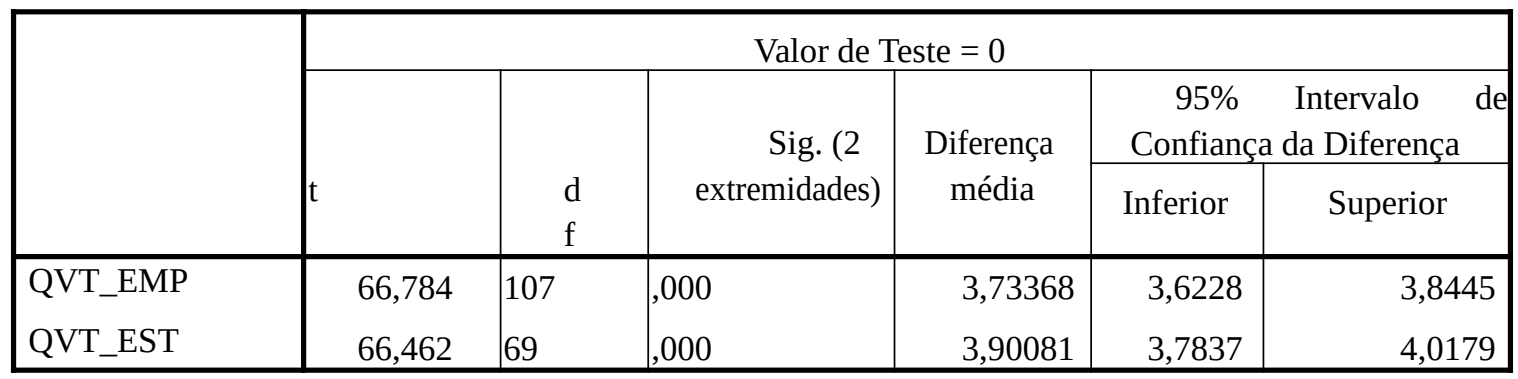

É possível observar que o teste T-Student comprovou que as diferenças entre as médias são significativas estatisticamente, ou seja, o nível de significância é 0,000 para ambas as dimensões. Portanto, embora sejam discretas as diferenças de percepção de QVT entre os estagiários e os empregados, ainda são significativas, como mostra a análise de GAP utilizada para identificar as diferenças entre os grupos, conforme o gráfico 3.

Gráfico 3 - Análise de GAP entre empregados versus estagiários -

Dados obtidos e trabalhados pelas autoras (2019)

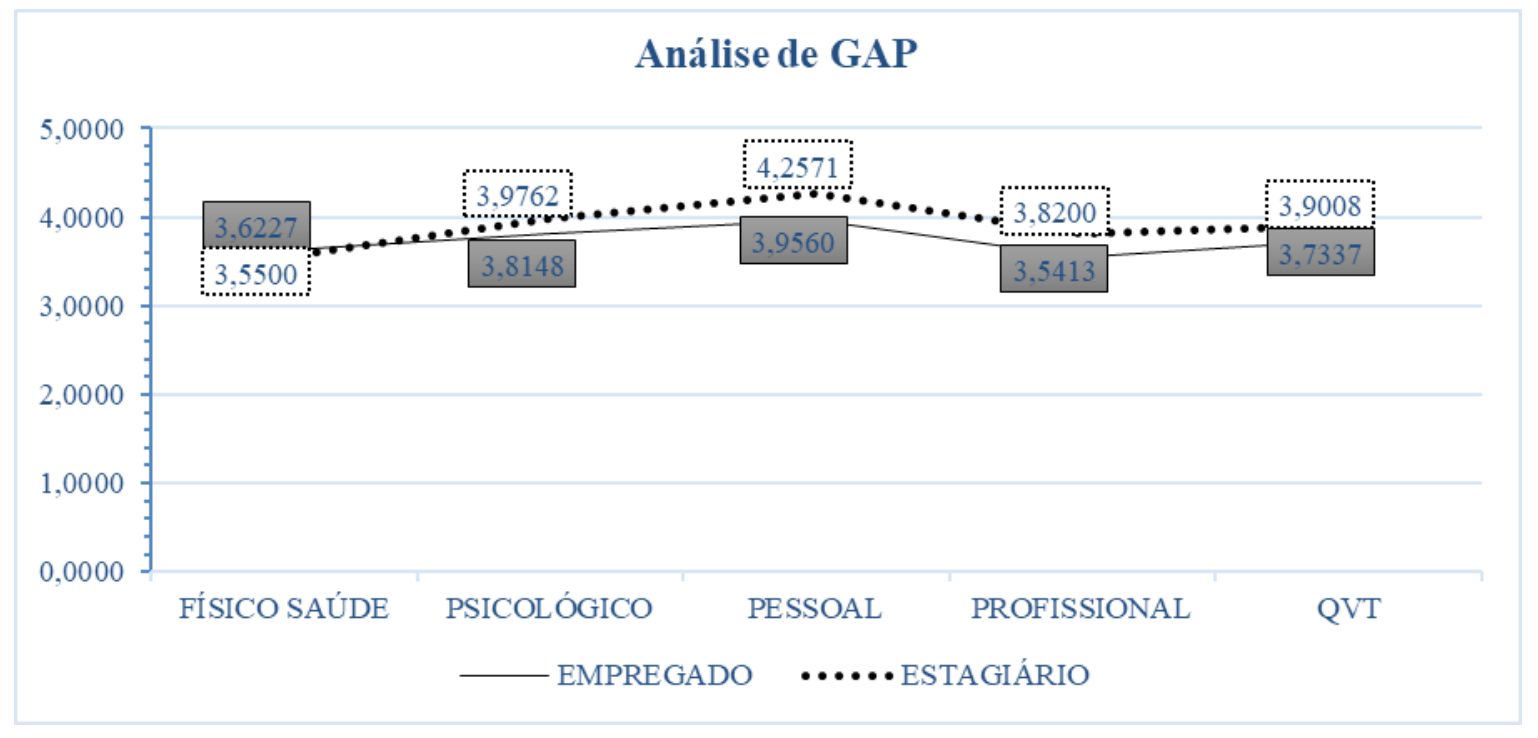

O domínio que apresentou maior variação entre os grupos foi o pessoal, talvez porque seja o domínio onde predominam maiores expectativas, como a de autoavaliação. Portanto, pode-se dizer que os indicadores são de responsabilidade do próprio estagiário, ou seja, dependem de suas próprias atitudes. Não havendo en- 
tão a necessidade de intervenção de terceiros ou da empresa para elevar esse índice, teoricamente é mais sim ples manter níveis satisfatórios de QVT nesse domínio.

A questão do domínio Físico/Saúde, foi o que apresentou menor variação entre os grupos estudados, nesse sentido pode-se deduzir, portanto, que estão satisfeitos quanto ao direito a saúde e o atendimento das necessidades humanas fundamentais. É possível que ambos os grupos mantenham hábitos relativamente saudáveis, que aumentam a disposição e contribuem para um nível satisfatório de QVT.

A pesquisa realizada leva em consideração a QVT como a percepção de satisfação em relação a uma série de itens. No caso da empresa em questão, observou-se que a percepção da satisfação também está diretamente afetada por fatores socioeconômicos da região. Segundo Pilatti (2012) a motivação é um dos fenômenos intrínsecos ao indivíduo. O autor leva em consideração a teoria de Frederick Herzberg (1968), segundo a qual o salário é um fator higiênico e não motivacional, extrínseco ao indivíduo, ou seja, a ausência dele desmotiva, mas a presença não é elemento motivador. Pode-se afirmar que o salário representa a possibilidade de satisfazer as necessidades do indivíduo, o que é diferente de produzir motivação. Por mais que a pessoa seja muito bem remunerada, ela se "acostuma” a isso e se sente numa zona de conforto. Então, se não recebe um bom salário ela se desmotiva, mas o fato de receber um bom salário não significa que ela estará necessariamente motivada.

No que diz respeito ao estagiário, ele ainda está aprendendo, e se sente inseguro, tendo uma visão mais idealizada do ambiente organizacional. Deduz-se então que a insegurança pode levar a uma postura menos crítica em relação à organização. Nesta fase de aprendizado o colaborador não tem muitas referências e, por tanto, muitos parâmetros de comparação.

É notório que há uma diferença de faixa etária entre os grupos, nesse sentido é possível inferir que, ao mesmo tempo em que o estagiário é jovem e está aprendendo, tem uma visão mais positiva da realidade. Pode-se afirmar, talvez, que essa nova experiência é quase um deslumbre. Ou seja, há menos autocrítica e mais disposição e receptividade, o que pode ajudar a inibir a crítica. Diferente do empregado que já está há alguns anos e tem uma visão menos positiva e mais crítica, devido à rotina que já pode ter-se tornado monó tona, e na qual a percepção da QVT já não é tão alta, pois não há novidade, como acontece para o estagiário. Levando-se em conta o índice satisfatório obtido pelo domínio pessoal, pode-se concluir que todos os indicadores referentes à integração social, ou seja, preconceitos, privacidade e relacionamentos interpessoais estão sendo mantidos em um nível adequado especialmente pelos estagiários. Para Chiavenato (1990), a organização influencia no comportamento das pessoas no ambiente de trabalho, nessa perspectiva é importante que os colaboradores estejam satisfeitos. A satisfação não só melhora a qualidade no trabalho, como também aumenta a produtividade.

Esta pesquisa evidenciou que apesar de a QVT geral dos colaboradores estar dentro da classificação satisfatória, no caso dos empregados foi constatada uma menor satisfação em relação ao domínio profissional. Segundo Reis Júnior (2008), os empregados são muito dependentes da condição de trabalho, dos benefícios oferecidos pela empresa e das atitudes de responsabilidade social, logo, não dependem apenas de si mesmos para aumentar a QVT nesse aspecto. Percebeu-se uma menor satisfação dos empregados com a falta de autonomia e participação, falta de igualdade no trabalho, falta de espírito de camaradagem e desapontamento com os treinamentos.

Já os estagiários apresentaram menor satisfação em relação ao domínio físico/saúde, o que pode estar relacionado à falta de hábitos saudáveis, bem como à diferença de percepção devido aos benefícios sociais relacionados à questão e ofertados pela organização aos empregados. Para Reis Júnior (2008), este domínio 
contempla todos os aspectos relacionados à saúde, a doenças relacionadas ao trabalho e a hábitos saudáveis. E se algum destes aspectos está comprometido, a produtividade do estagiário estará diretamente afetada.

\section{CONSIDERAÇÕES FINAIS}

O objetivo do presente estudo foi realizar uma análise comparativa entre a percepção dos estagiários e dos empregados de uma empresa de grande porte do oeste do Paraná sobre qualidade de vida no trabalho. Os resultados apresentaram diferenças discretas, porém significativas, que puderam ser constatadas através do teste T-Student. Salienta-se que, nos resultados do QWLQ-bref, os domínios físico/saúde e profissional foram os que influenciaram na percepção com menor satisfação da QVT. É importante lembrar que esses domínios não estão relacionados somente aos colaboradores, mas também com a organização, no sentido de proporcio nar condições de trabalho, benefícios sociais e nas suas atitudes de responsabilidade social.

O fato de o domínio profissional dizer respeito, em grande parte, às condições oferecidas pela empresa, pode justificar, empiricamente, o baixo índice de satisfação constatado neste item. Infere-se que o empregado tende a ser mais crítico quanto às condições oferecidas pela empresa, em comparação aos outros três domínios, que abrangem, majoritariamente, aspectos pessoais (Facchini et al., 2015). Na questão físico/saúde, manter hábitos saudáveis certamente aumentará a disposição do estagiário e contribuirá para um aumento da QVT. Pode-se destacar que boas práticas de QVT são necessárias para o desempenho da empresa, evitando, entre outros aspectos, o absenteísmo e a falta de comprometimento. Para além da saúde física do trabalhador, as organizações precisam considerar aspectos psicológicos e sociais do ambiente de trabalho, assim como o bom relacionamento interpessoal organizacional.

Embora a pesquisa tenha sido realizada em uma única empresa, restrita ao setor administrativo e, portanto, não seja possível generalizar os resultados, foi construída com base em uma amostra criteriosa e considerável, atingindo os objetivos propostos.

Evidencia-se que os estagiários têm percepção de melhor QVT em relação aos empregados da referida organização, o que abre novas perspectivas de pesquisa, tanto para a administração quanto para a educação, no concernente à importante etapa de formação profissional representada pelo estágio. As diferenças foram significativas, representando um levantamento que permite reflexão preliminar sobre a percepção da QVT por grupos organizacionais distintos, trazendo elementos que ensejam aprofundamento em pesquisas futuras. Portanto, para avançar cientificamente sobre o tema, sugere-se pesquisas qualitativas, o que permitiria analisar mais profundamente as tendências e especificidades, as diferenças e influências nas percepções de estagiários e empregados, levantando de forma mais minuciosa as razões de cada índice obtido. Um estudo desta natureza poderia contribuir para ações visando a melhoria do cenário organizacional em diversos aspectos, bem como para ampliar a compreensão do processo de estágio, o que permitiria qualificar a mediação educacional e as orientações para a formação profissional.

\section{REFERÊNCIAS}

ALVES, E. F. (2010). Qualidade de vida no trabalho: indicadores e instrumentos de medidas. Diálogos \& Saberes, 6(1), 77-87. Disponível em: <https://nbn- resolving.org/urn:nbn:de:0168-ssoar-348252>. Acesso em 25 de julho de 2018.

REICHERT, C.D.M.; ODERICH, C. Qualidade de Vida no Trabalho: Análise Comparativa entre Estagiários e Empregados de Empresa do Oeste Paranaense.
Pleiade, 15(33): 45-62, Jul.-Dez., 2021

DOI: $10.32915 /$ pleiade.v15i33.708 
BRASIL. Consolidação das Leis do Trabalho. Decreto-Lei nº 5.442, de 01.mai.1943. Disponível em: <http://www.planalto.gov.br/ccivil_03/Decreto- Lei/Del5452compilado.htm>. Acesso em: 12 de setembro de 2019.

BRASIL. Lei n. 11.788, de 25 de setembro de 2008. Dispõe sobre o estágio de estudantes. Disponível em: <http:// www.planalto.gov.br/ccivil_03/_ato2007-2010/2008/lei/111788.htm>. Acesso em: 12 de setembro de 2019.

CHEREMETA, M.; PEDROSO, B.; PILATTI, L. A.; KOVALESKI, J. L. Construção da versão breviada do QWLQ-78: um instrumento de avaliação da qualidade de vida no trabalho. Revista Brasileira de Qualidade de Vida. Universidade Tecnológica Federal do Paraná - UTFPR Ponta Grossa - PR - Brasil. v. 03, n. 01, jan./jun. 2011, p. 01-15. Disponível em: <https://periodicos.utfpr.edu.br/rbqv/article/view/758>. Acesso em: 11 de agosto de 2018.

CHIAVENATO, I. Recursos Humanos. São Paulo: Atlas, 1990.

CHIZZOTTI, A. Pesquisa em ciências humanas e sociais. 2ºdição. Cortez Editora. 2001.

FACCHINI, Y. M. G. A. AREÃO, A. S. LENK, T. U. M. Qualidade de vida no trabalho dos professores tutores das redes pública e privada de educação. São João da Boa Vista/SP, 05/2015. Disponível em: <http://www.abed.org.br/congresso2015/anais/pdf/BD_147.pdf>. Acesso em 26 de julho de 2018.

GOMES, R. K.; CLAUMANN, P. D C.; CARRERA, L.C.M.; ZANARDI, E. Os Benefícios e Dificuldades na Gestão da Qualidade de Vida no Trabalho. Revista Administração de Empresas. Centro Universitário de Curitiba, v.13, n.14, 2014.

HAIR, J.F; BLACK, W.C.; BABIN B. J.; ANDERSON, R. E.; TATHAM, R. L. Análise Multivariada de Dados. 6. ed. Porto Alegre: Bookman, 2009.

HESKETH, J. L.; COSTA, M. T. P. M. Construção de um instrumento para medida de satisfação no trabalho. Revista de Administração de Empresas. Rio de Janeiro, 20(3): 59-68, jul./ set. 1980. Disponível em: <http://dx.doi.org/ 10.1590/S0034-75901980000300005>. Acesso em 26 de abril de 2019.

LIMONGI-FRANÇA, A. C. Qualidade de vida no trabalho: conceitos e práticas na sociedade pós-industrial. São Paulo: Atlas, 2004.

LOPES, A. C. B., LEINIOSKI A da C., CECCON, L. Testes t para comparação de médias de dois grupos independentes. Universidade Federal do Paraná - UFPR/2015.

MARTINS, D. de A. Qualidade de vida: evolução dos conceitos e práticas no século XXI. In: Vilarta, R.; Gutierrez, L. G.; Monteiro, M. I. (Orgs). Considerações sobre a Qualidade de Vida no Trabalho e o Estresse Ocupacional. Campinas: Ipes, 2010. Cap.14 p.131-140.

MENDES, R. A.; LEITE, N. Ginástica laboral: princípios e aplicações práticas. Barueri, SP: Manole, 2004.

MUNDSTOCK, E.; FACHEL, J. M. G.; CAMEY, S. A.; AGRANONIK, M. Introdução à análise estatística utilizando o SPSS 13.0. Universidade federal do Rio Grande do Sul. Instituto de Matemática. Caderno de Matemática e Estatística. Porto Alegre, 2006.

NEUMANN, A D. Programas de estágio: a precarização do trabalho, as perspectivas dos estudantes e o cumprimento da lei 11.788/08. Universidade Federal Do Rio Grande Do Sul. Porto Alegre/RS, 2017. Disponível em: <https://lume.ufrgs.br/handle/10183/180471>. Acesso em 08 de maio de 2019.

OLIVEIRA, S. R de. Estágios para universitários: representações e implicações na inserção profissional dos jovens brasileiros e franceses. Tese de doutorado. Programa de pós- graduação em Administração/UFRGS. Porto Alegre, 2009. Disponível em: < https://www.lume.ufrgs.br/handle/10183/18329>. Acesso em 20 de maio de 2019.

PILATTI, L. A. Qualidade de Vida no Trabalho e a Teoria dos Dois Fatores de Herzberg: Possibilidades-Limite das Organizações. Revista Brasileira de Qualidade de vida. Universidade Tecnológica Federal do Paraná - UTFP. Ponta

REICHERT, C.D.M.; ODERICH, C. Qualidade de Vida no Trabalho: Análise Comparativa entre Estagiários e Empregados de Empresa do Oeste Paranaense.
Pleiade, 15(33): 45-62, Jul.-Dez., 2021

DOI: 10.32915/pleiade.v15i33.708 
Grossa, v. 04, n. 01, jan. /jun. 2012, p. 18-24. Disponível em: <https://periodicos.utfpr.edu.br/rbqv/article/view/ 1195/801>. Acesso em 05 de março de 2019.

PILATTI, L. A. Qualidade de Vida e Trabalho: perspectivas na sociedade do conhecimento. Estratégias e Políticas em Qualidade de Vida. Campinas: IPES Editorial, 2005. p. 41-50. Disponível em: <https://www.fef.unicamp.br/fef/sites/ uploads/deafa/qvaf/tecnologia_cap5.pdf>. Acesso em 10 de abril de 2019.

PILATTI, L. A.; BEJARANO, V. C. Qualidade de vida no trabalho: leituras e possibilidades no entorno. Gestão da qualidade de vida na empresa. Campinas: IPES Editorial, 2005. p. 85-104.

PRESTES, É. R. N.; VIEIRA J. L. A qualidade de vida no trabalho e a satisfação do estagiário do curso de administração em duas instituições públicas contratantes no município de Parintins - AM. Revista Observatorio Economía Latinoamericana, Brasil, Março, 2017. Disponível em: <http://www.eumed.net/cursecon/ecolat/br/17/qualidade.html>. Acesso em 30 de junho de 2019.

REIS JÚNIOR, D. R. Qualidade de Vida no Trabalho: construção e validação do questionário QWLQ-78. 2008. 114 f. Dissertação Mestrado Programa Pós-Graduação em Engenharia de Produção, UTFPR. Ponta Grossa. 2008. Disponível em: <http://www.pg.utfpr.edu.br/ppgep/dissertacoes/arquivos/101/Dissertacao.pdf $>$. Acesso em 10 de novembro de 2018.

SAMPAIO, J. dos R. Qualidade de Vida no Trabalho: Perspectivas e Desafios Atuais. Universidade Federal de Minas Gerais. Revista Psicologia: Organizações e Trabalho. 12(1), jan-abr 2012, pp. 121-136. ISSN 1984-6657.

SANTANNA, A. S. \& Kiliminik, Z. M. (Org.). Qualidade de vida no trabalho: abordagens e fundamentos. Rio de Janeiro: Elsevier, 2011.

SILVA, C. S. C. TEIXEIRA, M. A. P. Experiências de Estágio: Contribuições para a Transição Universidade-Trabalho. Universidade Federal do Rio Grande do Sul, Porto Alegre/RS. jan.-abr. 2013, Vol. 23, No. 54, 103-112.

SILVA, D. D. M. DA, Valores e Qualidade de Vida no Trabalho: Estudo de Caso em uma Rede Supermercadista. Universidade Federal de Santa Maria - UFSM/ Centro de Tecnologia - CT / Programa de Pós-Graduação em Engenharia de Produção. Santa Maria/RS, 2013.

SIQUEIRA, D. M. C. Estilo e Qualidade de Vida no Trabalho: Um Estudo com Profissionais de Educação a Distância. 2014. 126 f. Dissertação (Mestrado) - Curso de Mestrado Profissional em Sistema de Informação e Gestão do Co nhecimento, Faculdade de Ciências Empresariais, Universidade FUMEC, Belo Horizonte, 2014. Disponível em: <http:// www.fumec.br/revistas/sigc/article/view/2587/1625>. Acesso em: 01 de agosto de 2019.

SIVIEIRO, I. M. P. S. Saúde mental e qualidade de vida de enfartados. 2003. 111f. Tese (Doutorado) - Escola de Enfermagem de Ribeirão Preto, USP, São Paulo.

SOUZA, A. C de; Alexandre, N. M. C.; Guirardello E. B. Propriedades psicométricas na avaliação de instrumentos: avaliação da confiabilidade e da validade. Epidemiol. Serv. Saude, Brasília, 26(3):649-659, jul-set 2017. Disponível em: <https://doi.org/10.5123/S1679-49742017000300022>. Acesso em 08 de novembro de 2019.

VALORIA, C. S.; CZARNESKI, F.; CERQUEIRA L. S. Análise da qualidade de vida no trabalho dos alunos do iceac/furg em atividades de estágio. Porto Alegre, RS, Brasil, 2016.

VIEIRA, A. A qualidade de vida no trabalho e o controle da qualidade total. Florianópolis: Insular, 1996.

REICHERT, C.D.M.; ODERICH, C. Qualidade de Vida no Trabalho: Análise Comparativa entre Estagiários e Empregados de Empresa do Oeste Paranaense.
Pleiade, 15(33): 45-62, Jul.-Dez., 2021

DOI: 10.32915/pleiade.v15i33.708 